Document downloaded from:

http://hdl.handle.net/10251/140916

This paper must be cited as:

Salinas Marín, I.; Gimenez Valentin, MH.; Cuenca Gotor, VP.; Seiz Ortiz, R.; Monsoriu Serra, JA. (05-2). Design and evaluation of a three-dimensional virtual laboratory on vector operations. Computer Applications in Engineering Education. 27(3):690-697. https://doi.org/10.1002/cae.22108

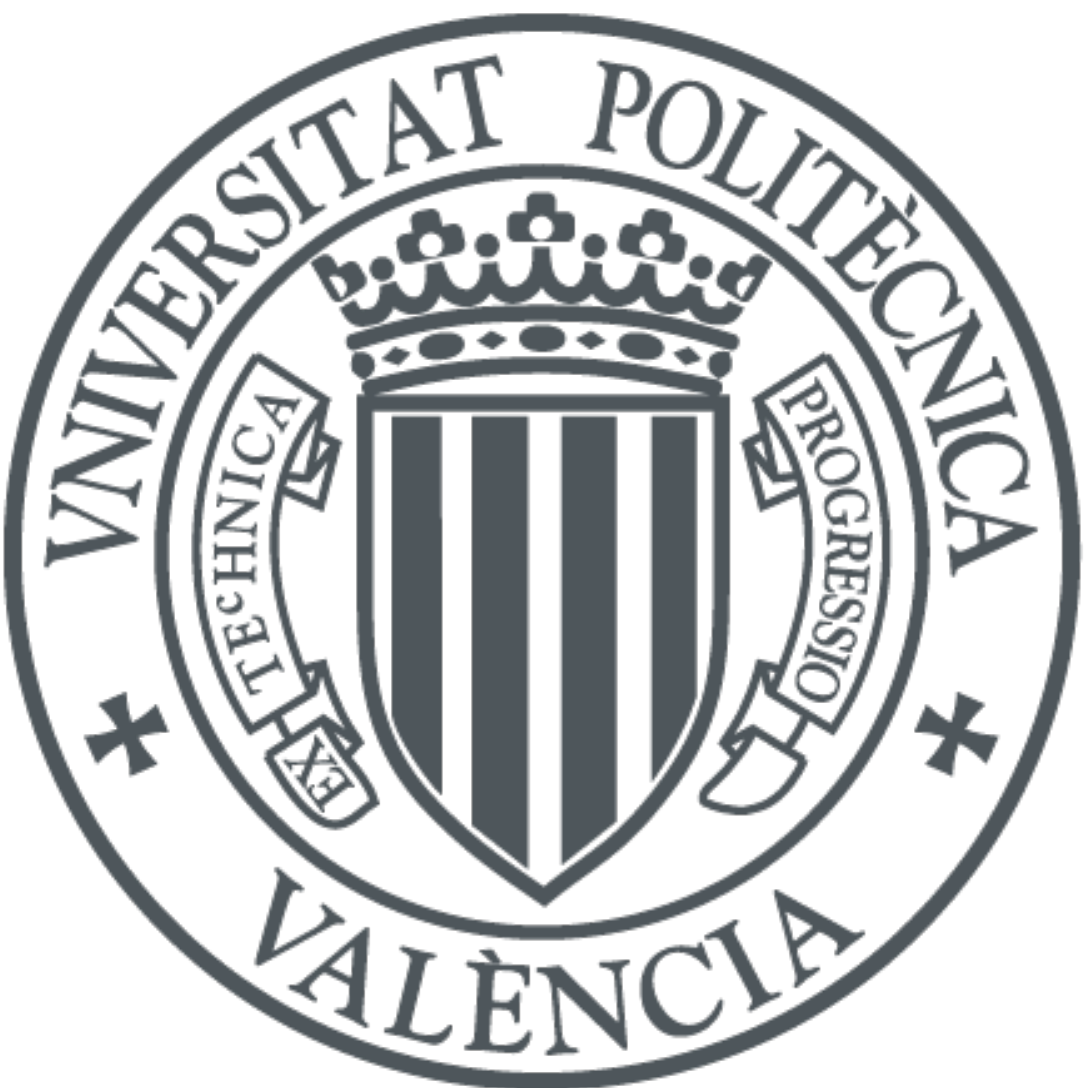

The final publication is available at https://doi.org/10.1002/cae.22108

Copyright John Wiley \& Sons

Additional Information 


\title{
Design and evaluation of a 3D virtual laboratory on vector operations
}

\author{
Isabel Salinas ${ }^{1, *}$, Marcos H. Giménez ${ }^{1}$, \\ Vanessa P. Cuenca-Gotor ${ }^{2}$, Rafael Seiz-Ortiz ${ }^{3}$, and Juan A. Monsoriu ${ }^{1}$ \\ ${ }^{1}$ Centro de Tecnologías Físicas, Universitat Politècnica de València, 46022 València, Spain. \\ ${ }^{2}$ Instituto de Diseño para la Fabricación y Producción Automatizada, Universitat Politècnica de \\ València, 46022 Valencia, Spain. \\ ${ }^{3}$ Departamento de Lingüistica Aplicada,Universitat Politècnica de València, 46022 Valencia, Spain. \\ *E-mail: isalinas@fis.upv.es
}

\begin{abstract}
In Physics, many quantities are vectors, and their use requires typical operations such as addition, substraction, scalar multiplication, scalar product (dot product), vector product (cross product) and scalar triple product. This is a very basic topic in all General Physics courses for Engineering degrees. However, we have detected that some students lack a deep understanding of vector operations and their properties. In this work, we present a virtual laboratory (developed using the tool "Easy Java Simulations") for the study and understanding of these topics. The user can introduce the components of the input vectors and gets a $3 \mathrm{D}$ representation, which can be scaled and rotated for a better visualization. Any of the aforementioned operations can be selected, and the result is shown both numerically and graphically. The user can also modify any represented vector. In this way, the virtual lab provides a real time visualization of how the change affects the result. The possibility of limiting the changes to either magnitude or direction is also included. The efficiency of the virtual laboratory has been tested analyzing the results obtained in two groups of students (virtual laboratory vs. traditional resources). A satisfaction survey has been also carried out.
\end{abstract}

Keywords: virtual laboratory, Physics, Easy Java, vector analysis. 


\section{Introduction}

In Mechanics-related topics taught in Physics subjects during the first years of Engineering degrees, students must acquire a series of fundamental concepts that may be hard to understand or difficult to master. Virtual Laboratories are among the most versatile tools for students to foster this kind of learning $[1,2]$. Firstly, they place the focus on active learning, using tools with which learners nowadays are very familiar and which present significant advantages in education, such as interactivity and dynamic response scenarios [3]. Secondly, Virtual Laboratories are not necessarily restricted to the faster completion of a typical exercise, but can also enable the control of variables in a process and, therefore, contribute to the analysis of their influence, additionally showing the necessary representations (images, graphs, animations) to comprehend the underlying concepts and relations. In this way, they are a support tool for the development of crosscurricular competences, such as concept comprehension and integration, problem analysis and resolution and critical thinking, among others. In such a context, learning processes based on virtual laboratories have shown a series of advantages [4], although their pedagogical efficiency is determined by a thorough integration within the global teaching project $[5]$.

In this work the design and evaluation of a new virtual laboratory is presented which is aimed at the study and comprehension of vector operations and their properties; such as, addition, subtraction, scalar multiplication, scalar product, vector product and mixed product [6]. These operations are involved in a large number of basic Physics relations. For example, the Newton's Second Law states that an addition of vectors (forces) is equal to a scalar multiplication (mass by acceleration); the work is defined as a scalar product (force by displacement); and the magnetic force is related to a vector 
product that involves the magnetic flux density [7]. Therefore, vector calculus is usually present at Physics book chapters (see Chapter 3 of Ref. [7]), and online classes [8].

The virtual laboratory developed here provides a real-time visualization of these operations and shows how changes in the involved parameters affect the final result. This virtual laboratory has been developed using the tool "Easy Java Simulations" (EJS) [9], based on Open Source Physics [10]. EJS is a free tool that allows the user to create interactive applets in Java or JavaScript (HTML5), mainly for learning or teaching purposes. The tool allows object-oriented programming, and therefore the lab is composed by a large number of functions. For example, the simple code that calculates the angle between two vectors is:

$$
\begin{aligned}
& a \text { Magn }=\text { Math.sqrt }\left(a x^{*} a x+a y^{*} a y+a z * a z\right) ; \\
& \text { bMagn=Math.sqrt }\left(b x * b x+b y^{*} b y+b z * b z\right) ; \\
& \text { angle=Math.acos }\left(\left(a x^{*} b x+a y^{*} b y+a z^{*} b z\right) / a M a g n / b M a g n\right) ;
\end{aligned}
$$

Since the virtual laboratory has been developed in three vehicular languages (English, Spanish and Valencian), this fact means yet another feature that makes it ideal to be used in educational contexts to implement the teaching approach known as CLIL (Content and Language Integrated Learning) [11]. This means the teaching of a specific content (vectors in our case) through a language different from the students' first language, and therefore provides the process with an interesting dual aim. This is obviously a remarkable added value of the learning tool, which makes it ideal to be used in bilingual and multilingual educational contexts.

For the evaluation of the laboratory, several surveys have been administered to students by means of the PoliformaT platform (https://poliformat.upv.es), with the aim of knowing their opinion, as well as ascertaining the utility and clarity of the virtual laboratory, and to carry out a feedback process. The learning outcomes of two pilot groups 
of students have also been compared, one of them implementing the present virtual laboratory and the other one using a traditional teaching methodology.

With the objective of assessing the influence of the use of the vector virtual laboratory on students' learning, two control groups of learners were selected during the academic year 2017/18, belonging to the first year of two different degrees at the School of Design Engineering of the Universitat Politècnica de València, and two subjects whose programs include vectors as a topic. One group, studying the subject Complements of Physics [12] in the Mechanical Engineering Degree, was taught in a traditional way, whereas the virtual laboratory was used with the other group who were studying Basic Physics for Engineering [13] in the Electrical Engineering degree.

\section{Development of the innovation}

The Vector Virtual Laboratory [6] allows the learner to introduce the components of three vectors and one scalar and to select one of the six available operations: addition, subtraction, scalar product (dot product), vector product (cross product) and scalar triple vector product, as well as scalar and vector multiplication). The vectors and the result of the operation (if the latter is a vector) are shown as a $3 \mathrm{D}$ representation in which the user may modify in an interactive way both the point of view and the scale. As an alternative to the manual introduction of vector components, the user may modify them by dragging the tip in the viewer. In this way, he or she can interactively observe how modifications affect the result of the selected operation. Dragging of the tip of the vector may be free, it may only affect its magnitude or it may simply change its orientation. Additionally, the user can make use of copy and paste buttons, in order to use, for instance, the result of an operation as the operand for another one. The laboratory also includes buttons for 
visualizing different geometric properties of interest, such as: the angle between two vectors, the projection of a vector on the other, the parallelogram they form or the parallelepiped formed by three vectors.

Figure 1 shows a screenshot of the virtual laboratory. The viewer depicts a 3D representation of an orthonormal reference system, together with the additional elements and vectors. This representation is fully interactive, including the possibility of dragging with the mouse the tip of a vector in order to modify it. This can also be done with any other point so as to change the perspective point of view. The scale is controlled through the slider "Zoom", located in the "Display" panel. Since the mouse pointer moves in two dimensions, it is not possible to modify the three components of a vector simultaneously through dragging. As a consequence, only two of them may vary (and the ones that may vary depend on the perspective point of view). Nevertheless, it is possible to control any single component by clicking on the corresponding key. For example, if the tip of a vector is dragged while pressing key $\mathrm{X}$, only that component changes.

The "Operands" panel (Figure 2a) allows the learner to introduce specific numerical values for the three components of any vector and it shows automatically the corresponding magnitude on the right. When writing on a numerical field, the background color is yellow. The INTRO key is used to validate the entry, and then the background becomes white. If the background color becomes red instead, that means the entry is not a valid number. One can also introduce the value of a scalar to use it in the operation of multiplication by a vector. It is worth pointing out that each vector has a color associated with it (blue, green, purple) which allows the vector to be quickly identified, both in the viewer and in the different panels. The "Operands" panel includes different control buttons. In addition to the copy and paste ones mentioned above, it has the block button 
(components cannot be modified, neither in the viewer nor in the panel sections) and the buttons used to transform into a unit vector.

The "Operation" panel (Figure 2b) is used to choose one of the six available operations. When the result is a scalar, its value is shown in the "Result" panel. If the result is a vector, the panel shows its components and magnitude, and it is also depicted in red in the viewer. For example, Figure 3 displays the result of different operations applied to the vectors $(-1 ; 2 ; 2)$ and $(2 ; 3,1)$. The "Interesting values" panel (Figure $2 b$ ) displays the values of four relevant geometric properties: the angle between two vectors, the projection of one vector on another one, the area of the parallelogram they form and the volume of the parallelepiped formed by three vectors. By using the corresponding open/close eye buttons, a given graphic representation may be enabled or disabled. For instance, Figure 4 shows the angle between vectors as well as the projection of one over the other, whereas Figure 5 represents the parallelogram formed by two vectors and the parallelepiped formed by three of them. The "Display" panel enables students to control different representation options. For example, the drop-down list "Addition/substraction" controls the way of graphically representing the corresponding operation (Figure 6), either by means of the parallelogram rule or as the successive application of operands.

\section{Results}

\subsection{Evaluation method}

With the aim of assessing the influence of the use of the Vector Virtual Laboratory on students' actual learning outcomes, two control groups of students were selected during the 2017-18 academic year. Both groups belonged to the first year of two bachelor degrees from the School of Design Engineering (Universitat Politècnica de València, 
Spain), and two subjects that included the topic Vectors within their syllabi. In the group doing the subject "Complements of Physics" [12] from the Mechanical Engineering degree, the topic Vectors was taught in a traditional way, whereas in the group doing the subject "Basic Physics for Engineering" [13] from the Electrical Engineering degree, the virtual laboratory was used.

To be able to analyse the effects of the use of the virtual laboratory on the academic performance of students, a series of tests, which were of the open-numericalresponse type, were conducted with the help of the exam tool within the institutional online platform known as "PoliformaT" which belongs to the Sakai project https://sakaiproject.org. In order to meet this objective, an initial exam was administered, prior to the teaching of the topic, to establish the students' initial knowledge level about the topic Vectors. Later on, once the topic was taught using any of the two methodologies, another exam was conducted using the same platform and testing method. Additionally, with the purpose of assessing the degree of satisfaction on the students' part with regard to the use of the virtual laboratory, an anonymous survey was conducted. This survey addressed seven questions and the responses were sorted around five levels: TDA (I totally disagree); DA (I disagree); IND (Indifferent); A (I agree); and TA (I totally agree).

\subsection{Academic performance test}

In the first place, when comparing the results from the tests conducted before teaching the topic, it was observed that the mean value of the scores was very similar in the two groups: in "Basic Physics for Engineering" with a mean of 5,4 and a standard deviation of 2,5, whereas in "Complements of Physiscs" the mean was 5,2 and the standard deviation was 2,9. As expected, the mean scores of the tests administered after the teaching of the topic were significantly higher in both groups. In "Basic Physics for 
Engineering", the new mean score was 9,1, with a standard deviation of 1,5; in "Complements of Physiscs", in turn, the new mean value was 8,3 and the standard deviation was 1,9. The graphs included in Figure 7 show that the test scores were in both cases clearly higher after teaching the topic, and they presented lesser dispersion. However, it can also be seen that in the group using the virtual laboratory a higher percentage of students obtained the highest score. In fact, the mean score of the students from the group using the virtual laboratory increased by $68 \%$, compared with a $60 \%$ increase of the group following a traditional methodology.

Nevertheless, given that the normal development of the course did not permit test circumstances to be exactly the same for both groups, it can not be conclusively concluded that the improvement of results after teaching the topic was a direct consequence of the use of the virtual laboratory. For this reason, an opinion survey was conducted whose results are discussed in the next section.

\subsection{Opinion survey}

The opinion survey was administered, naturally, to the group of students that had used the virtual laboratory. Table 1 shows the questions and answers obtained from a sample of 30 students. The answers to the questions regarding the usability of the virtual laboratory indicate that over $75 \%$ of students explored the options offered by this tool (Q6) and $90 \%$ of them found that the use of the virtual laboratory was intuitive and easy (Q2). The perception of students regarding their improvement in the comprehension of the topic Vectors, after using the virtual laboratory, is also very positive, since $83 \%$ of users state that they have improved (Q4) and that it has been useful for them (Q1).

Given the importance of motivation in the learning process, question Q5 aimed at assessing the motivational effect of the virtual laboratory compared with using more 
traditional materials such as notes, handouts, slides, and the like. Figure 8a shows the percentage of students answering this question at each of the five possible levels. It can be observed that a very high percentage $(83 \%)$ of students found the use of the virtual laboratory more motivating, whereas $17 \%$ of students either did not find it more motivating at all (7\%) or did not find any difference (10\%). Question 7 is concerned with the general assessment of the laboratory. As can be seen in Figure 8b, assessment by the students is very positive, since $90 \%$ of them either agreed or totally agreed with the statement that it is good.

\section{Conclusions}

This work presents a virtual laboratory designed to help learners to strengthen their knowledge and understanding of vectors and their properties. The use of this tool, which allows students to introduce different vectors, visualize their 3D representation and operate with them, provides a simple and comprehensive approach to vector calculus. The satisfaction survey showed a high degree of motivation on the part of the students who used this tool, which was reflected in a significative increase in the percentage of students obtaining higher marks in the test.

\section{Acknowledgements}

The authors would like to thank the Instituto de Ciencias de la Educación (Institute of Education Sciences) at the Universitat Politècnica de València (UPV) for its support to the teaching innovation groups MoMa and e-MACAFI and for providing financial aid to the PIME B24 teaching innovation project. 


\section{References}

[1] A. Vidaurre, J. Riera, M.H. Giménez, and J.A. Monsoriu, Contribution of digital simulation in visualizing physics processes, Comput. Appl. Eng. Educ., Vol. 10, 2002, pp. $45-49$.

[2] C. Depcik and D.N. Assanis, "Graphical user interfaces in an engineering educational environment," Comput. Appl. Eng. Educ. Vol. 13, 2005, pp. 48-59.

[3] A. Jimoyiannis and V. Komis, Computer simulations in physics teaching and learning, Comput. Educ., Vol. 36, 2001, pp. 183-204.

[4] F. Esquembre, Computers in physics education, Comput. Phys. Commun., Vol. 147, 2002, pp. 13-18.

[5] R.N. Steinberg, Computers in teaching science: To simulate or not to simulate, Am.J. Phys., Vol. 68, 2000, S37-S41.

[6] M.H. Giménez, I. Salinas, and J. A. Monsoriu, Visualizador de operaciones con vectores (español/valencià/english), 2017, http://hdl.handle.net/10251/84650 Accesed 1 February, 2019.

[7] P.A. Tipler and G. Mosca, Physics for scientists and engineers, New York, NY, USA: W.H. Freeman, cop., 2008.

[8] R. Nave, HyperPhysics, 2016, http://hyperphysics.phy-astr.gsu.edu/hbase/hph.html Accesed 1 February, 2019.

[9] F. Esquembre, Easy Java Simulations: a software tood to create scientific simulations in Java", Comput. Phys. Commun, Vol. 156, 2004, pp. 199-204. 
[10] W. Christian and M. Belleni, Physlets: Teaching physics with interactive curricular material, Upper Saddle River, NJ, USA: Prentice Hall, 2001.

[11] D. Marsh, Content and Language Integrated Learning (CLIL). Development Trajectory, University of Córdoba, 2012.

[12] Complements of Physics, course description (2017) online at http://www.upv.es/titulaciones/GIM/menu_1015238i.html Accesed 1 February, 2019. [13] Basic Physics for Engineering, course description (2017) online at http://www.upv.es/titulaciones/GIEL/menu 1014686i.html Accesed 1 February, 2019. 
Table 1: Questions and results of the opinion survey.

\begin{tabular}{|l|l|c|c|c|c|c|}
\hline \multicolumn{2}{|l|}{ Question } & TDA & DA & IND & A & TA \\
\hline Q1 & The Vector Virtual Lab was useful for me. & 0 & 2 & 3 & 10 & 15 \\
\hline Q2 & $\begin{array}{l}\text { The use of the Vector Virtual Lab was easy } \\
\text { and intuitive for me. }\end{array}$ & 0 & 0 & 3 & 7 & 20 \\
\hline Q3 & $\begin{array}{l}\text { In general, my level of comprehension } \\
\text { regarding the concepts before using the } \\
\text { Vector Virtual Lab was good. }\end{array}$ & 0 & 5 & 4 & 14 & 7 \\
\hline Q4 & $\begin{array}{l}\text { My level of comprehension regarding the } \\
\text { has improved as compared with my } \\
\text { previous level. }\end{array}$ & 0 & 3 & 2 & 21 & 4 \\
\hline Q5 & $\begin{array}{l}\text { It is more motivating for me to study the } \\
\text { topic vectors using the Vector Virtal Lab } \\
\text { than studying it with the material provided } \\
\text { by the teachers (notes, handouts, slides... }\end{array}$ & 2 & 0 & 3 & 11 & 14 \\
\hline Q6 & $\begin{array}{l}\text { When I have used the vector Virtual Lab, I } \\
\text { have explored many of the options it offers. }\end{array}$ & 0 & 0 & 7 & 10 & 13 \\
\hline Q7 & $\begin{array}{l}\text { My general assessment and opinion } \\
\text { regarding the Vector Virtual Lab is } \\
\text { positive. }\end{array}$ & 0 & 0 & 3 & 10 & 17 \\
\hline
\end{tabular}




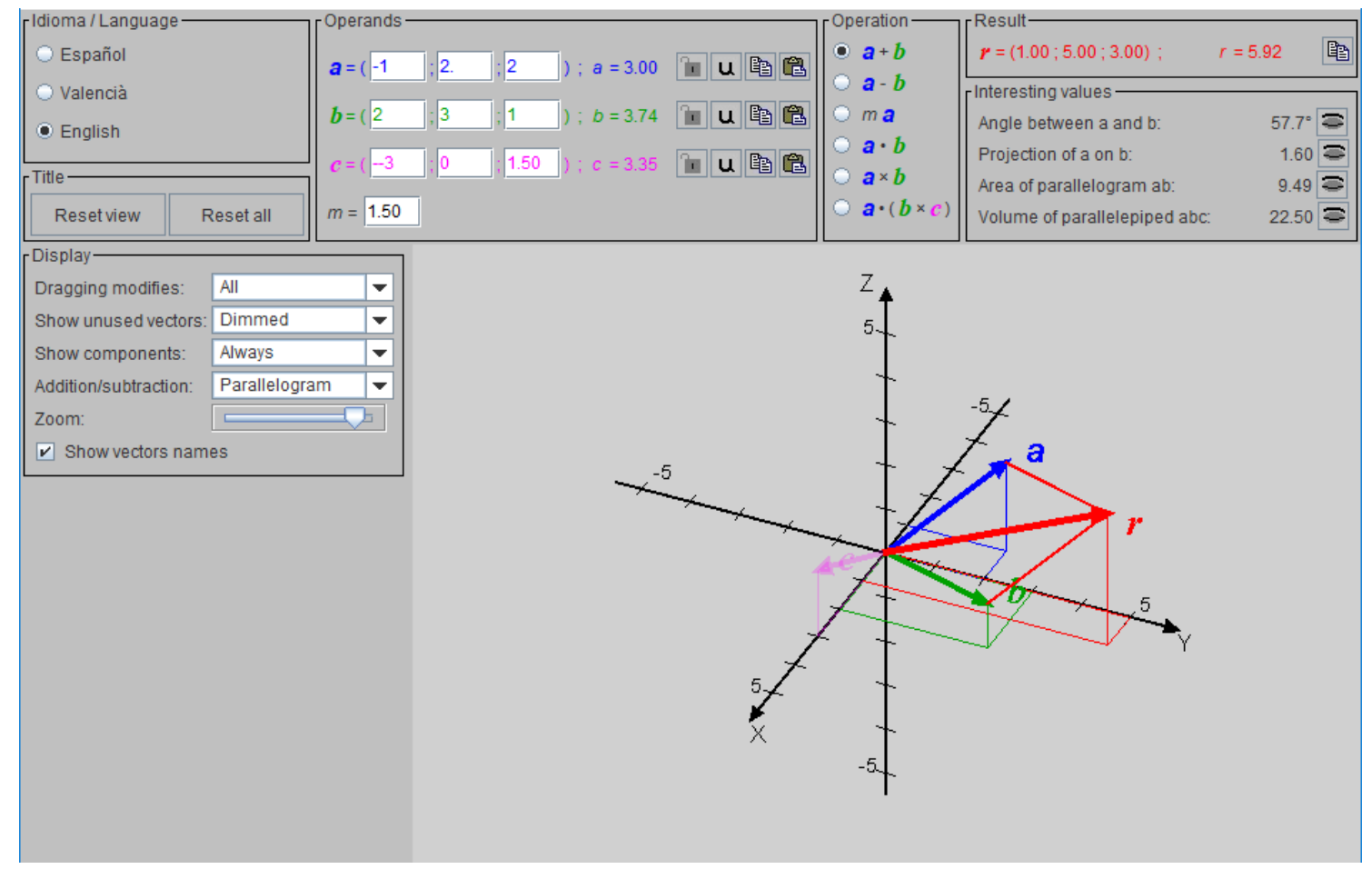

Figure 1: Interface of the virtual laboratory. 
(a)

\begin{tabular}{|c|c|c|c|c|c|c|c|}
\hline $\mathbf{a}=(-1$ & ; 2. & 2 & ); $a=3.00$ & 7 & $u$ & 蕮 & 递 \\
\hline $\boldsymbol{b}=(2$ & 3 & 1 & ); $b=3.74$ & 1 & $u$ & 窞 & 娣 \\
\hline$c=(-3$ & 0 & 1.50 & ); $c=3.35$ & 1 & $u$ & 舄臽 & 娣 \\
\hline$m=1.50$ & & & & & & & \\
\hline
\end{tabular}

(b)

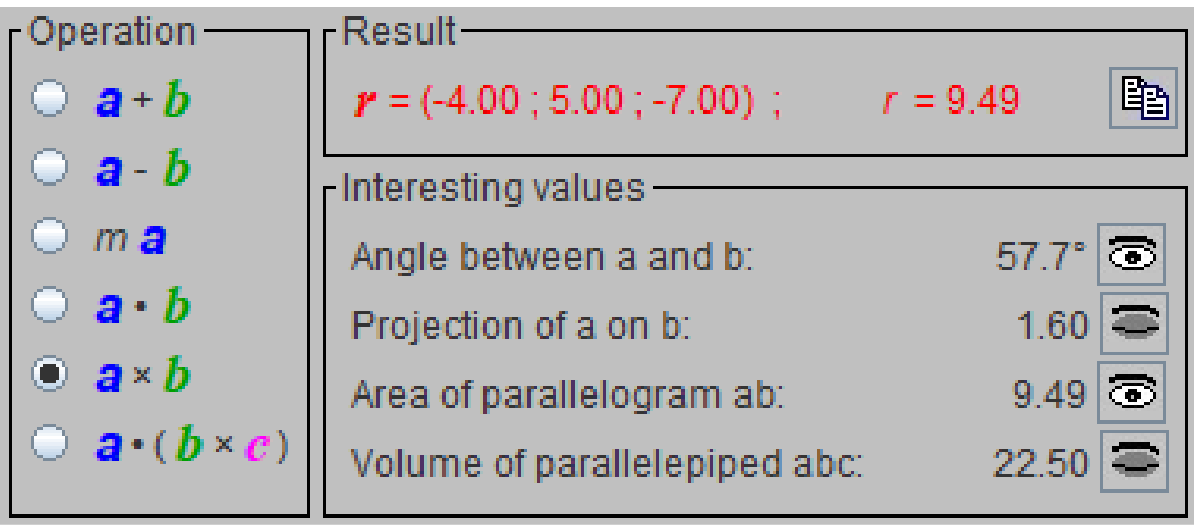

Figure 2: a) Detail of the "Operands" panel; b) Detail of the "Operation", "Result" and “Interesting values" panels. 
(a)

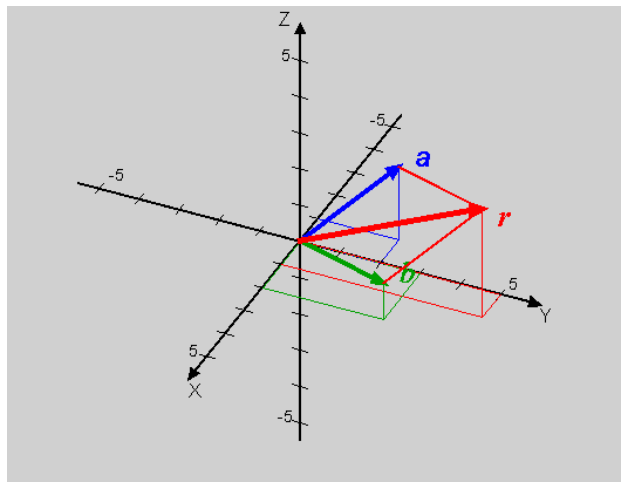

(c)

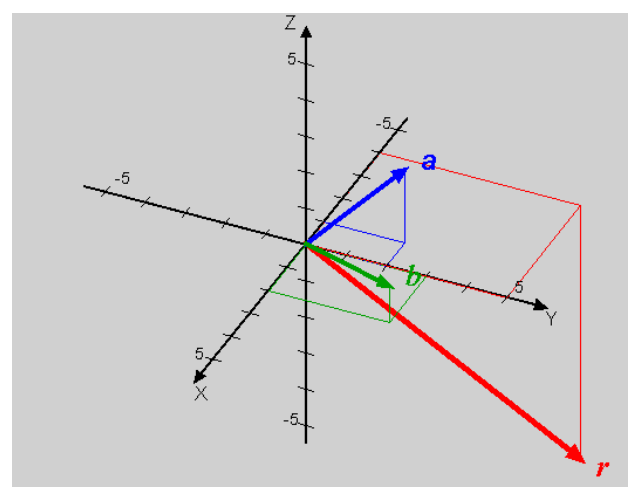

(b)

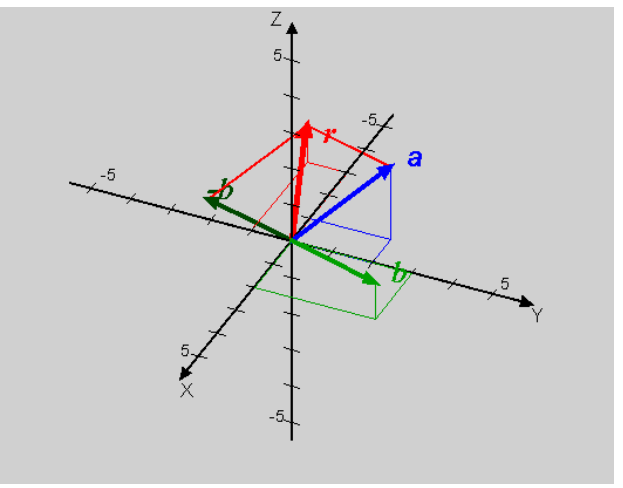

(d)

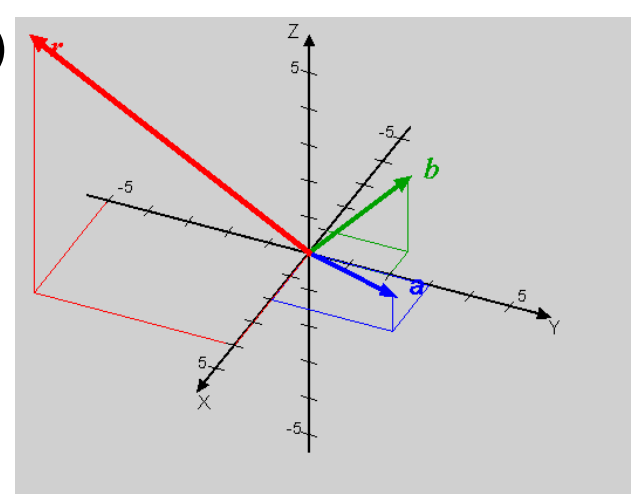

Figure 3: Visualization of results of operations: a) $(-1 ; 2 ; 2)+(2 ; 3 ; 1)$; b) $(-1 ; 2 ; 2)-(2 ; 3 ; 1)$;

c) $(-1 ; 2 ; 2) \times(2 ; 3 ; 1)$ d $)(2 ; 3 ; 1) \times(-1 ; 2 ; 2)$. 
(a)

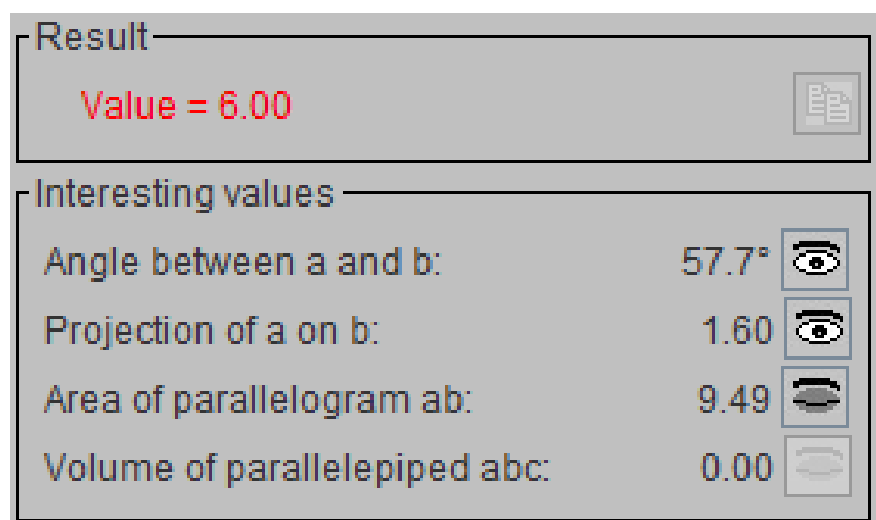

(b)

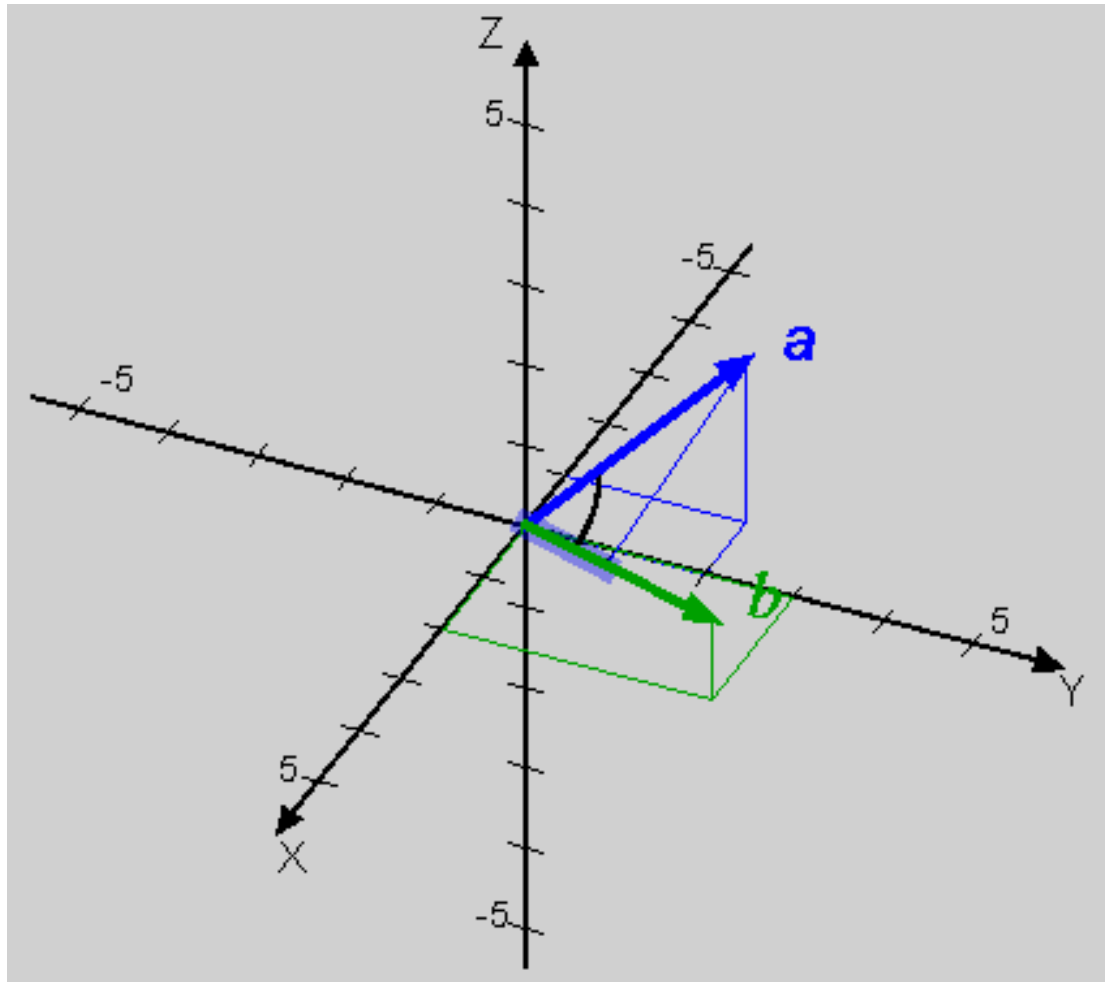

Figure 4: Scalar product of $\boldsymbol{a}=(-1 ; 2 ; 2)$ and $\boldsymbol{b}=(2 ; 3 ; 1)$ : a) Numerical result and interesting values. b) Visualization of the projection of $\boldsymbol{a}$ on $\boldsymbol{b}$ and of the angle between the vectors. 
(a)

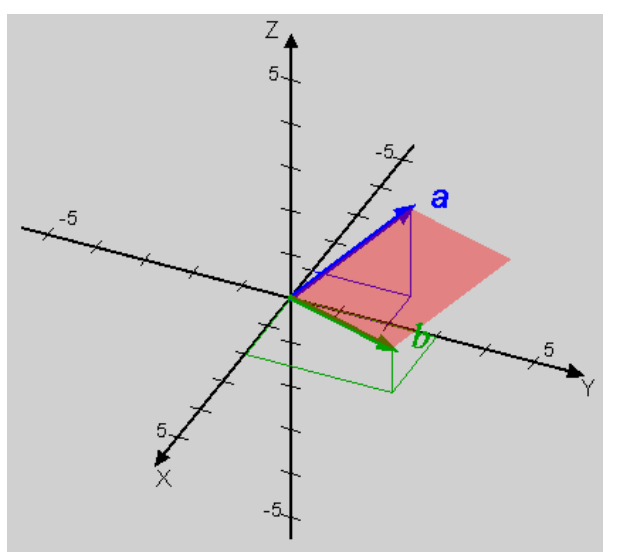

(b)

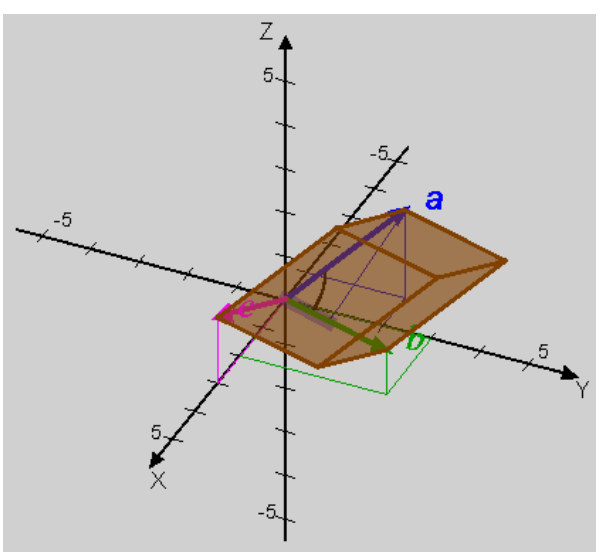

Figure 5: a) Parallelogram formed by $\boldsymbol{a}=(-1 ; 2 ; 2)$ and $\boldsymbol{b}=(2 ; 3 ; 1)$; b) Parallelepiped formed by $\boldsymbol{a}=(-1 ; 2 ; 2), \boldsymbol{b}=(2 ; 3 ; 1)$ and $\boldsymbol{c}=(3 ; 0 ; 1.5)$. 
(a)

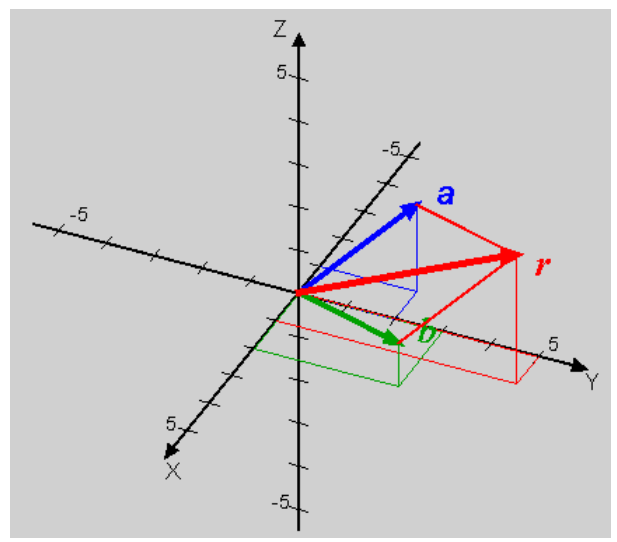

(b)

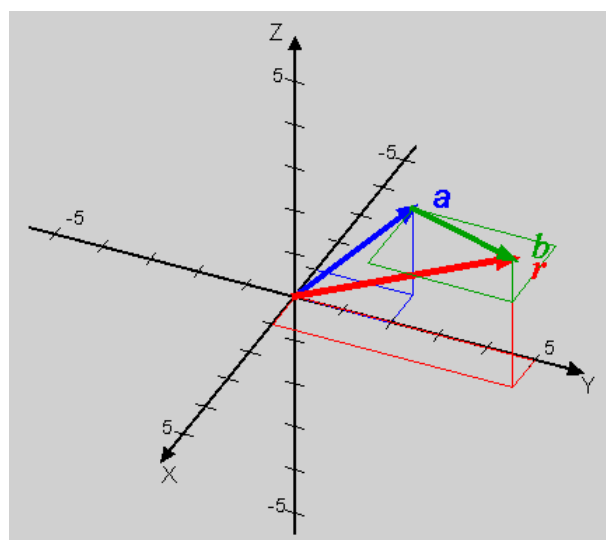

Figure 6: Addition of $\boldsymbol{a}=(-1 ; 2 ; 2)$ and $\boldsymbol{b}=(2 ; 3 ; 1)$ : a) parallelogram rule; b) vector sequence. 
Basic Physics for Engineering

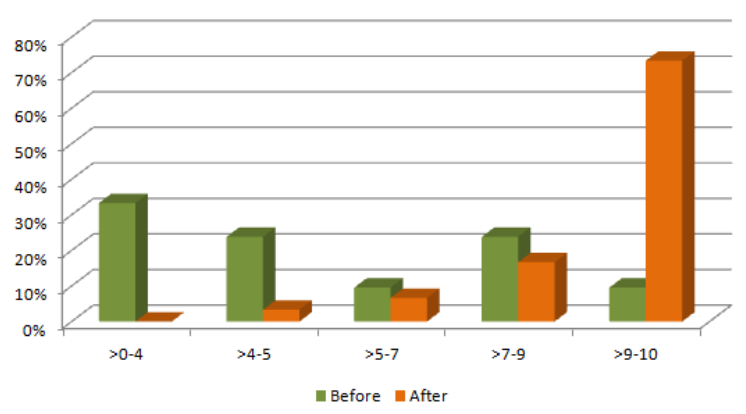

Complements of Physics

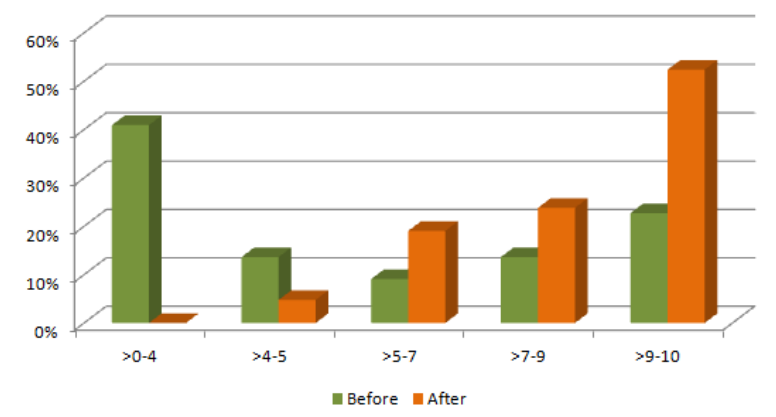

Figure 7: Percentage of students who have reached a score in the tests of each group, before and after teaching the topic. 
Q5 - It's more motivating

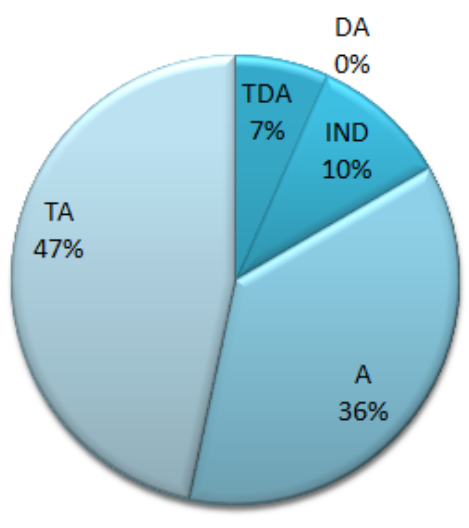

Q7 - Laboratory assessment

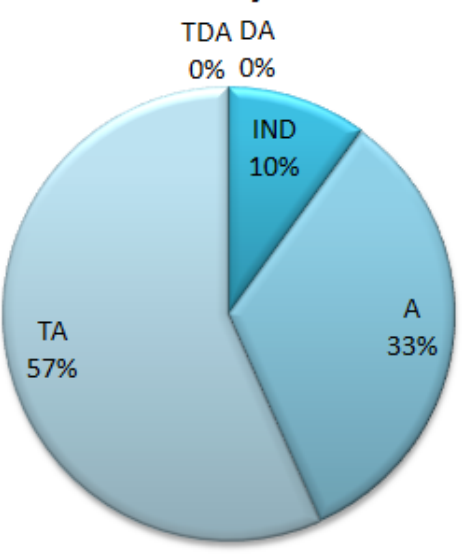

Figure 8: Percentage of students answering Q5 and Q7 at each of the five different levels. 